\title{
Artrite reumatoide: uma visão atual
}

Primeira submissão em 09/11/10 Última submissão em 06/05/11 Aceito para publicação em 01/06/11 Publicado em 20/10/11

\author{
Rheumatoid arthritis: a current view
}

Isabela Goeldner'; Thelma L. Skare²; Iara T. de Messias Reason ${ }^{3}$; Shirley Ramos da Rosa Utiyama ${ }^{4}$

unitermos
Artrite reumatoide
Autoanticorpos
Diagnóstico

\section{resumo}

Introdução: A artrite reumatoide (AR) é uma doença autoimune inflamatória e crônica que afeta aproximadamente $1 \%$ da população adulta mundial. A doença caracteriza-se pela inflamação do tecido sinovial de múltiplas articulações, levando a destruição tecidual, dor, deformidades e redução na qualidade de vida do paciente. Sua etiologia é complexa e em grande parte desconhecida, porém estudos demonstram a influência de fatores genéticos e ambientais em sua patogênese. Devido à forte influência genética, familiares de pacientes com AR formam um grupo de risco para o desenvolvimento da doença, principalmente em sua forma mais grave. Apesar de seu elevado potencial incapacitante, o curso da AR pode ser modificado por meio do diagnóstico precoce e do manejo adequado do paciente. No entanto, o diagnóstico precoce da AR é ainda bastante difícil diante da heterogeneidade das manifestações clínicas da doença, o que acaba retardando a implantação terapêutica. $O$ tratamento da AR baseia-se no uso de anti-inflamatórios não esteroidais (AINEs), corticosteroides, drogas antirreumáticas modificadoras do curso da doença (DMARD) e agentes imunobiológicos. Além da terapia medicamentosa, também são adotadas medidas como educação do paciente e terapias psico-ocupacionais. Atualmente, estudos têm se voltado à identificação de fatores preditores de doença mais grave, como autoanticorpos como fator reumatoide (FR) e anticorpo antipeptídio cíclico citrulinado (anti-CCP), que constituem importantes marcadores imunológicos de diagnóstico e prognóstico da AR. Discussão e conclusão: Apesar dos significativos avanços tanto no entendimento como no diagnóstico e no tratamento da AR, ainda persistem inúmeros desafios a serem superados.

\section{abstract}

Introduction: Rheumatoid arthritis (RA) is a chronic autoimmune inflammatory disease, which affects approximately $1 \%$ of the world's adult population. It is characterized by the inflammation of synovial tissue from multiple articulations, leading to tissue destruction, pain, deformities and reduced quality of life. RA etiology is complex and largely unknown, although studies support the influence of genetic and environmental factors on its pathogenesis. Due to its major genetic component, relatives from RA patients are part of the risk group, mainly as to the development of the most severe forms. In spite of its high disability risk, RA development can be affected through early diagnosis and adequate therapy. Nonetheless, its early diagnosis is still very demanding due to the heterogeneity of its clinical presentations, which delays therapeutic approach. RA treatment includes non-steroidal anti-inflammatory drugs, corticosteroids, disease-modifying antirheumatic drugs (DMARD), and immunobiologic agents. Furthermore, raising patient's awareness and developing psyco/occupational therapies are also part of the therapeutic approach. Currently, several studies focus on the identification of predictive factors for severe RA such as rheumatoid factor (RF) and anti-cyclic citrullinated peptide (anti-CCP) autoantibodies, which are major immunological diagnostic and prognostic markers for RA. Discussion and conclusion: Despite the fact that there has been substantial progress in the investigation, diagnosis and treatment of $R A$, there are still several challenges to be overcome.

1. Mestra e doutoranda em Ciências Farmacêuticas da Universidade Federal do Paraná (UFPR); pesquisadora no Laboratório de Imunopatologia do Hospital de Clínicas (HC) da UFPR.

2. Doutora em Princípios de Cirurgia pela Faculdade Evangélica de Medicina do Paraná (FEMPAR); professora da FEMPAR; médica do Serviço de Reumatologia do Hospital Evangélico de Curitiba.

3. Doutora em Imunologia pela Universidade de Lübeck, Alemanha; professora da UFPR; pesquisadora e responsável pelo Laboratório de Imunopatologia do HC-UFPR.

4. Doutora em Ciências Farmacêuticas pela UFPR; professora da UFPR; pesquisadora no Laboratório de Imunopatologia do HC-UFPR. 


\section{Introdução}

\section{Artrite reumatoide}

A artrite reumatoide (AR) é uma doença autoimune (DAl) sistêmica comum, cuja prevalência é estimada em 1\% da população mundial ${ }^{(1)}$. Sua prevalência varia de acordo com as características étnicas da população, detectando-se de $0,1 \%$ em camponeses africanos até $5 \%$ em populações indígenas Tlingit, Yakima, Pima e Chippewa ${ }^{(21)}$. Ao sul da Europa, a taxa de incidência anual da AR é de 16,5 casos $/ 10^{5}$ habitantes; já ao norte, essa incidência sobe para 29 casos $/ 10^{5}$ habitantes. Por sua vez, na América do Norte, ocorrem 38 casos $/ 10^{5}$ habitantes ${ }^{(1)}$. No Brasil, Marques et al. ${ }^{(47)}$ verificaram a prevalência variando de $0,2 \%$ a $1 \%$ da população.

Durante anos, a AR foi considerada uma doença de caráter benigno, porém estudos mais recentes mostraram que, devido a seus efeitos deletérios sobre a mobilidade física e a capacidade funcional, assim como a persistência do processo inflamatório (aterosclerose acelerada), pacientes com AR têm sua expectativa de vida significativamente diminuída quando em comparação com a população em geral $^{(60,71)}$. Aproximadamente $50 \%$ dos indivíduos com AR ficam impossibilitados de trabalhar em 10 anos a partir do início da doença, o que representa significativo impacto econômico e social(20). Nesse contexto, um entendimento maior da etiopatogênese da AR, bem como dos avanços no arsenal terapêutico, torna-se necessário(14, 22, 42).

\section{Fatores de patogenicidade na AR}

O desenvolvimento das DAls é influenciado por fatores hormonais, ambientais e imunológicos, que atuam em conjunto sobre indivíduos geneticamente suscetíveis. Estudos ao longo do tempo têm mostrado que a superposição desses fatores é determinante para o desenvolvimento da $A R$, já que o efeito isolado dos mesmos não causa DAl( ${ }^{(38)}$.

Calcula-se em $60 \%$ a contribuição genética para o desenvolvimento da AR. Os fatores genéticos estão fortemente associados à positividade do anticorpo antipeptídio cíclico citrulinado (anti-CCP) e à resposta do paciente ao tratamento ${ }^{(65,69)}$. Diversos locci já foram relacionados com o desenvolvimento da AR, sendo os alelos HLA-DRB1 a principal associação genética, estando também associados ao desenvolvimento de formas mais graves da doença ${ }^{(8,62)}$.

Os alelos HLA-DRB1 compartilham sequências de aminoácidos glutamina-leucina-arginina-alanina-alanina
(QRRAA, RRRAA ou QKRAA) chamadas epítopo comum (shared epitope [SE]), conservadas nas posições 71-75 da terceira região de hipervariabilidade da cadeia beta da molécula HLA-DRB1 ${ }^{(33)}$. Numerosos estudos têm sido conduzidos a fim de esclarecer a relação entre a presença desses alelos e o desenvolvimento da $A R$, porém até o momento não há uma explicação consensual.

Em relação ao sexo, sabe-se que a AR afeta três vezes mais mulheres do que homens, e diversos estudos têm relacionado o sexo feminino com o desenvolvimento de formas mais graves da doença. Essas constatações, porém, ainda são contraditórias ${ }^{(61,74)}$.

Estudos sugerem a influência de infecções por microrganismos na fisipatologia da AR por meio de mecanismos de mimetismo molecular. Entre os microrganismos mais estudados estão o Proteus mirabilis e o vírus Epstein-Barr ${ }^{(67)}$.

Alguns estudos clínicos e epidemiológicos evidenciam prevalência elevada de periodontite e perda dentária em pacientes com $A^{(15,24)}{ }^{(2)}$ Sugere-se ainda a periodontite como um possível fator desencadeador e mantenedor da resposta inflamatória autoimune na AR.

Por sua vez, já se encontra bem estabelecida a relação entre o uso de tabaco e a maior suscetibilidade ao desenvolvimento da AR em pacientes HLA-SE positivos ${ }^{(43,48)}$. Klareskog et al. ${ }^{(37)}$ demonstraram que, em pacientes portadores do HLA-SE, o cigarro acelera as reações de citrulinização em proteínas pulmonares, o que dispara a produção de autoanticorpos. O cigarro também afeta o curso da AR, elevando o aparecimento de nódulos reumatoides, bem como pode alterar o limiar da dor percebida pelo paciente ${ }^{(30,79)}$.

A influência de múltiplos fatores no desenvolvimento da AR corroboram a complexidade atribuída a seu desenvolvimento e tornam o entendimento da doença um desafio.

\section{Fisiopatogenia da AR}

A AR é resultante da ação das células T e B autorreativas, que levam à sinovite, à infiltração celular e a um processo desorganizado de destruição e remodelação óssea ${ }^{(19)}$. A membrana sinovial é a principal fonte de citocinas pró-inflamatórias e proteases e, em conjunto com osteoclastos e condrócitos, promove a destruição articular. Projeções de tecido proliferativo penetram na cavidade articular, invadindo a cartilagem e o tecido ósseo, formando o pannus, característico da $\mathrm{AR}^{(23)}$.

Diversas hipóteses tentam explicar a sequência de eventos observados na AR. A mais aceita sugere que 
modificações pós-traducionais induzidas por agentes ambientais tornam moléculas próprias imunogênicas. Em consequência da exposição prolongada ao cigarro ou a outros estímulos ambientais, a resposta do sistema imunológico adaptativo aos peptídios citrulinados pode preceder em anos o aparecimento dos sintomas clínicos da $A R^{(37,73)}$. Tanto o fribrinogênio como a vimentina citrulinados já foram identificados nas articulações de pacientes com AR e é provável que outras proteínas além dessas sofram reações de citrulinização ${ }^{(76,78)}$.

Apesar de a relação entre a positividade para o fator reumatoide (FR) e o desenvolvimento da AR não estar totalmente esclarecida, ambos estão intimamente relacionados. A presença de agregados de imunoglobulina do tipo $\mathrm{G}(\mathrm{lgG})$ ou de complexos de lgG-FR ativa o sistema complemento e resulta em diversos fenômenos inflamatórios. A ativação do sistema complemento pelos imunocomplexos pode ainda iniciar uma inflamação vascular com depósitos de FR em arteríolas, originando vasculites, cujo impacto na qualidade e na expectativa de vida do paciente é significativo ${ }^{(70)}$. Além disso, o reconhecimento dos complexos imunes por fagócitos promove liberação de diversas citocinas pró-inflamatórias, principalmente o fator de necrose tumoral alfa (TNF- $\alpha$ ), o que exacerba ainda mais o processo inflamatório ${ }^{(12)}$.

Recentemente, uma terceira classe de células $T$ auxiliadoras foi caracterizada como células CD4+ produtoras de interleucina 17 (IL-17). Células Th17 parecem conferir proteção contra infecções, promovendo a eliminação do microrganismo por meio do recrutamento de neutrófilos e da ativação de macrófagos no sítio da infecção(5,55).

Estudos recentes evidenciam um importante papel das células Th17 na modulação das respostas autoimunes relacionadas com AR e esclerose múltipla, doenças anteriormente consideradas Th1 dependentes. No que diz respeito à AR, as células Th17 parecem determinar o desenvolvimento da sinovite e a destruição articular por meio da interação com células dentríticas, macrófagos e células $B^{(49)}$.

\section{Familiares de pacientes com AR}

A ocorrência de casos de AR em uma mesma família é relativamente comum. $\mathrm{O}$ risco estimado de familiares de pacientes com AR desenvolverem a doença é de $4 \%$ para irmãos, 4,7\% para pais e filhos e 1,9\% para familiares de segundo grau. Por sua vez, familiares de primeiro grau de pacientes com AR em sua forma erosiva podem ter mais de $15 \%$ de chance de desenvolver a doença ${ }^{(29)}$.
Recentes estudos em populações nativas norte-americanas encontraram positividade de $19 \%$ para o anti-CCP em familiares saudáveis de pacientes com AR, e estudos na população brasileira revelaram positividade de $5,5 \%$ nos mesmos, o que contribui para a caracterização desses indivíduos como grupo de risco para o desenvolvimento da doença ${ }^{(25,32)}$.

O interesse em familiares de primeiro e segundo graus de pacientes com AR e os fatores de risco envolvidos no desencadeamento da doença é objeto de estudos há anos. Esses trabalhos sugerem que a agregação familiar, além dos aspectos genéticos, possa estar associada também ao sexo e à idade de início da doença no familiar afetado $(27,39,40)$.

Rojas-Villarraga et al. ${ }^{(58)}$ demonstraram que a história familiar é o principal fator relacionado com o tempo necessário para o surgimento de erosão articular significativa. Os autores sugerem que pacientes com AR, cuja história familiar seja positiva, possuem $200 \%$ mais de chances de desenvolver lesão articular substancial do que indivíduos da mesma faixa etária sem história familiar.

Estudos comparativos entre gêmeos têm sido desenvolvidos visando estimar a contribuição genética para o desenvolvimento da AR. Em populações caucasianas, essa contribuição se mostra em torno de $50 \%$ a $60 \%(44,47,64,65)$. Entretanto, essa influência pode variar de acordo com a população estudada, em decorrência de variações nos fatores genéticos aditivos e não aditivos, bem como nos fatores ambientais envolvidos ${ }^{(75)}$.

\section{Manifestações clínicas}

A AR constitui uma doença inflamatória crônica progressiva, sendo caracterizada por sinovite com envolvimento preferencial de articulações de mãos e punhos, de caráter simétrico e aditivo. As manifestações clínicas da AR podem ter início em qualquer idade, embora sejam observadas com mais frequência na quarta e quinta décadas de vida. A AR pode se manifestar de forma bastante variável, desde manifestações mais brandas, de menor duração, até uma poliartrite progressiva e destrutiva, associada a vasculite e outras manifestações extra-articulares ${ }^{(66)}$.

As articulações mais frequentemente afetadas são as sinoviais periféricas, como metacarpo e metatarsofalangianas, tornozelos e punhos. No entanto, também pode haver comprometimento de joelhos, ombros, cotovelos e quadris. Articulações como a temporomandibular, as articulações sinoviais da coluna e a laringe são ocasionalmente afetadas, o que pode dificultar o diagnóstico ${ }^{(31)}$. 
Edema, dor e calor local são características das articulações afetadas, que podem ainda apresentar rubor local. Deformações articulares ocasionadas por inflamação persistente, como boutonnière ou em "pescoço de cisne", são características da AR não tratada (Figura 1).

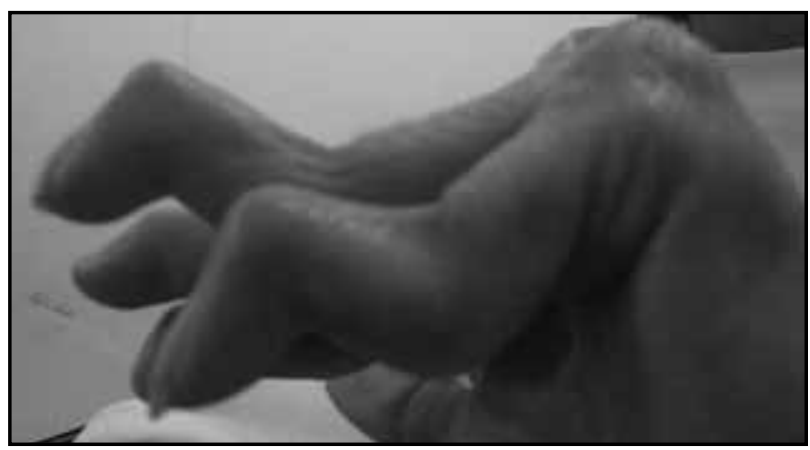

Figura 1 - Deformação em "pescoço de cisne"

Além dos sintomas articulares, manifestações extra-articulares são observadas em aproximadamente $50 \%$ dos pacientes, sendo a síndrome de Sjögren a mais comum. Outra manifestação extra-articular típica da AR é os nódulos reumatoides, que resultam da vasculite de pequenos vasos, e a consequente necrose com proliferação de fibroblastos e histiócitos epiteliais (Figura 2).

Complicações cardíacas e infecções estão associadas a altos índices de mortalidade entre os pacientes com $\mathrm{AR}^{(53)}$. A longo prazo, o prognóstico da AR pode ser considerado ruim, pois $80 \%$ dos afetados estão incapacitados após 20 anos, e sua expectativa de vida é reduzida em uma proporção de três a 18 anos $^{(2)}$. Com o advento de novas opções terapêuticas (p. ex., tratamento com biológicos) e o reconhecimento da importância do controle agressivo do processo inflamatório, essa perspectiva tende a melhorar. Prevenir dano articular e conseguir remissão têm se tornado alvos possíveis de serem alcançados. Embora agentes biológicos como os anti-TNF- $\alpha$ tenham demonstrado atuar de maneira positiva na diminuição da aterosclerose, ainda não se demonstrou redução da taxa de mortalidade em AR nos últimos 50 anos ${ }^{(63)}$.

\section{Diagnóstico da $A R$}

O diagnóstico da AR é feito por meio da associação de dados clínicos, laboratoriais e radiográficos ${ }^{(7)}$.

Estudos têm evidenciado a importância do tratamento precoce e adequado da $A R^{(16,68)}$. Em 2010, o Colégio Americano de Reumatologia (ACR) em conjunto com a Liga Europeia contra o Reumatismo (EULAR) publicaram os novos critérios diagnósticos para AR, que são direcionados

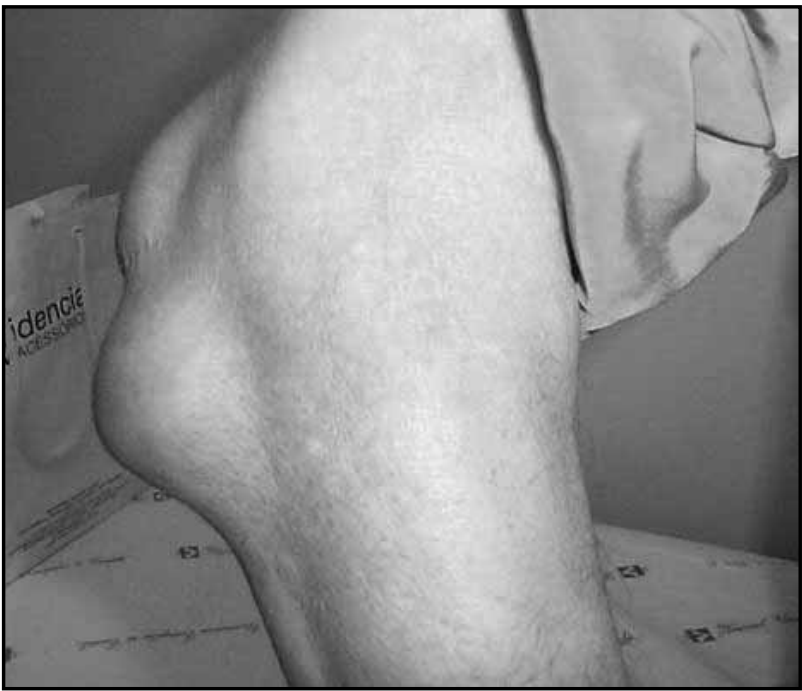

Figura 2 - Nódulos reumatoides em cotovelo

para o diagnóstico precoce da doença em pacientes que se apresentam com sintomatologia de curta duração.

A população-alvo para esses novos critérios é formada de: (a) pacientes com ao menos uma articulação edemaciada, caracterizada clinicamente como sinovite clínica, e (b) pacientes com sinovite que não pode ser explicada por outra doença, como lúpus eritematoso sistêmico (LES), artrite psoriática ou gota. Se persistirem dúvidas quanto à possibilidade desses diagnósticos, é necessária a consulta com reumatologista.

Esses novos critérios têm como base um sistema de graduação de sintomas de acordo com a Tabela a seguir.

Quando o resultado da soma dos itens de $A$ a $D$ é igual ou superior a seis, os achados correspondem à AR definida. Embora pacientes com somatório inferior a seis não sejam considerados com AR, os mesmos podem ser retestados e os critérios, completados de maneira cumulativa no decorrer do tempo ${ }^{(4)}$.

Exames de imagem sofisticados têm contribuído de forma significativa para o diagnóstico precoce da AR. Atualmente, a ressonância magnética (RM) é a técnica de imagem que traz mais benefícios ao diagnóstico da doença, pois evidencia precocemente alterações tanto de tecidos moles quanto de cartilagem e ossos.

A determinação do FR é amplamente utilizada no diagnóstico da AR, porém os resultados devem ser criteriosamente ponderados diante da especificidade limitada do exame. Em contrapartida, os anticorpos anti-CCP possuem elevada especificidade e sensibilidade semelhante ao FR, o que torna a determinação do anti-CCP uma ferramenta de grande utilidade para o diagnóstico da AR. 


\section{Tabela Critérios classificatórios para AR (ACR e EULAR, 2010)}

Critérios

A Envolvimento articular - por envolvimento entende-se edema ou sensibilidade à palpação, que pode ser confirmado por exames de imagem. Excluem-se: interfalangianas distais, primeira carpometacarpiana e primeira tarsometatarsiana

- 1 articulação grande (cotovelos, ombros, joelhos, coxofemorais e tornozelos)

- 2-10 articulações grandes (cotovelos, ombros, joelhos, coxofemorais e tornozelos)

- 1-3 articulações pequenas (com ou sem envolvimento de articulações grandes). São articulações pequenas: metacarpofalangianas, interfalangianas proximais, segunda a quinta metatarsofalangianas, interfalangianas do hálux e punhos

- 4-10 articulações pequenas (com ou sem envolvimento de articulações grandes). São articulações pequenas: metacarpofalangianas, interfalangianas proximais, segunda a quinta metatarsofalangianas, interfalangianas do hálux e punhos

- +10 articulações (com pelo menos uma articulação pequena incluída)

B Sorologia - o resultado de pelo menos um teste é necessário para a classificação

- FR negativo e anti-CCP negativo (valores inferiores ou iguais ao limite fornecido pelo laboratório)

- FR positivo fraco ou anti-CCP positivo fraco (valores positivos fracos = até três vezes o limite positivo fornecido pelo laboratório)

- FR fortemente positivo ou anti-CCP fortemente positivo (valores fortemente positivos = três vezes acima do limite positivo fornecido pelo laboratório)

C Reagentes de fase aguda - o resultado de pelo menos um teste é necessário para a classificação

- PCR e VHS normais

- PCR ou VHS alterados

D Duração dos sintomas autorreferidos pelo paciente

- $<6$ semanas

- $\geq 6$ semanas

Adaptado de Aletaha et al. (2010)(4).

AR: artrite reumatoide; ACR: Colégio Americano de Reumatologia; EULAR: Liga Europeia contra o Reumatismo; FR: fator reumatoide; anti-CCP: antipeptídio cíclico citrulinado; PCR: proteína C reativa; VHS: velocidade de hemossedimentação.

\section{Fator reumatoide}

O FR representa um grupo de autoanticorpos caracterizados pela habilidade de reagir com determinados epítopos da porção fragmento cristalizável $(\mathrm{Fc})$ da $\lg \mathrm{C}$ e atua ativamente na patogênese da $A R$, sendo sua presença sugestiva de prognóstico desfavorável(26,50). In vivo, o FR pode ser das classes IgA, IgG ou IgM, porém a classe IgM é a que se detecta sorologicamente com maior frequência ${ }^{(10)}$.

Teoricamente, um estímulo antigênico pode levar ao aparecimento de uma lgG anormal na sinóvia, resultando na produção de FR e no desenvolvimento posterior da doença reumática. Assim, o FR provavelmente não inicia o processo inflamatório na doença reumática, mas atua perpetuando e amplificando esse processo ${ }^{(59)}$.
O FR é utilizado com frequência para diferenciar AR de outras artrites crônicas, sendo que na AR geralmente é detectado em altos títulos. Sua sensibilidade é de aproximadamente $80 \%$ e sua especificidade, $70 \%$, podendo ocorrer na população sadia com prevalência que varia de $1 \%$ a $4 \%(31)$.

Outras doenças, como LES, síndrome de Sjögren, hepatite crônica ativa, hanseníase e algumas infecções parasitárias, podem mostrar positividade para esse anticorpo, embora sempre em títulos baixos ${ }^{(28,30)}$.

Tanto a existência do HLA-SE como o tabagismo já foram relacionados com a presença do $\mathrm{FR}^{(54)}$. A positividade para anti-CCP também está associada à positividade para FR, porém não são completamente coincidentes.

Jorgensen et al. ${ }^{(35)}$ demonstraram que a presença de níveis aumentados de FR IgA em pacientes com AR está 
associada ao desenvolvimento de doença erosiva, bem como a uma maior frequência de síndrome sicca concomitante. Estudos recentes sugerem ainda a associação entre a positividade para o FR IgA e a presença de anticorpos anti-CCP e títulos de FR IgM superiores a $50 \mathrm{UI} / \mathrm{ml}^{(50)}$.

Usualmente, o FR pode ser investigado no laboratório clínico por técnica de aglutinação em látex, que constitui um método de menor custo. Laboratórios de maior porte vêm empregando a turbidimetria e/ou nefelometria, considerando a vantagem da automação e maior rapidez na liberação dos resultados ${ }^{(10,28)}$. Nas situações em que se visa diferenciar o FR das classes $\lg \mathrm{A}$, $\lg \mathrm{G}$ ou $\lg \mathrm{M}$ são empregados testes imunoenzimáticos (ELISA), no entanto, estes ainda não se encontram amplamente disponíveis aos laboratórios de rotina em nosso meio ${ }^{(34) .}$ A variação na faixa de sensibilidade e especificidade dos métodos citados requer criteriosa interpretação do clínico, em associação aos dados do anti-CCP e dos sintomas do paciente.

\section{Anticorpo anti-CCP}

A busca por marcadores diagnósticos e prognósticos da AR tem sido objeto de inúmeros estudos. A citrulinização consiste na modificação pós-traducional de determinada proteína, na qual um resíduo de arginina é convertido em citrulina. Esse processo é catalisado pela enzima peptidil arginina deiminase (PAD) e neutraliza o caráter fortemente básico da arginina. Os anticorpos anti-CCP são produzidos localmente na membrana sinovial inflamada e no líquido sinovial de pacientes com $\mathrm{AR}^{(36,57)}$ e são capazes de reagir com diversos peptídios citrulinados(3).

Apesar de ser detectado ocasionalmente em pacientes sem $A R^{(18,72,77)}$, os testes imunoenzimáticos recentemente desenvolvidos para quantificação de anticorpos anti-CCP têm demonstrado sensibilidade de $67 \%$ e especificidade de $95 \%$ para $A R^{(52)}$. Estes constituem o teste de escolha na detecção do anti-CCP, sendo que já estão disponíveis ensaios de segunda (anti-CCP2) e terceira gerações (anti-CCP3) ${ }^{(33,52) .}$

Inúmeros estudos têm demonstrado que o aparecimento de autoanticorpos no soro de pacientes com AR pode preceder em anos os sintomas clínicos da doença ${ }^{(6,45,46,51,56)}$. A determinação dos anticorpos anti-CCP também parece ser útil no diagnóstico precoce da AR, principalmente em grupos de risco, como familiares de pacientes ${ }^{(25)}$.

Uma vez que os autoanticorpos podem ser detectados em fases precoces da AR, sua utilidade diagnóstica e prognóstica é notável, sendo considerados marcadores de pior prognóstico para a afecçãa ${ }^{(52)}$. O anticorpo anti-CCP também pode ser detectado nos pacientes FR negativo ${ }^{(78)}$.

A AR apresenta padrões de evolução distintos com diversos graus de incapacitação funcional e alterações extra-articulares que geram importante impacto social e econômico. Dessa forma, marcadores prognósticos possuem significativa importância para a identificação precoce de pacientes com formas mais grave da doença, o que possibilita a implantação racional do tratamento mais agressivo. Também são de muita utilidade por pouparem pacientes com formas mais brandas de possíveis efeitos tóxicos decorrentes de um tratamento mais agressivo. Medidas dessa natureza contribuem de forma significativa para a redução dos custos relacionados com a doença, tanto para o paciente como para a sociedade.

\section{Tratamento da AR}

No passado, acreditava-se que a AR fosse uma doença de caráter benigno e bom prognóstico. As terapias eram de baixo custo e visavam apenas ao controle dos sintomas, aguardando-se a regressão da doença. Entretanto, nas últimas décadas, a AR foi caracterizada como uma doença agressiva e associada ao aumento da morbidade e mortalidade dos pacientes. Diante desses fatos, a abordagem terapêutica da AR mudou radicalmente $e^{(9,17)}$.

Atualmente, o tratamento da AR consiste na adoção de diversas medidas, que incluem a educação do paciente e terapias psico-ocupacionais e medicamentosas ${ }^{(11,13)}$. Assim como em outras DAls, o tratamento da AR inclui drogas anti-inflamatórias não esteroidais (AINEs) e glicocorticoides (CGs) em baixa dosagem ou intra-articular, drogas antirreumáticas modificadoras do curso da doença (DMARD) e agentes imunobiológicos, cuja escolha é sempre com base no balanço entre eficácia e segurança( ${ }^{(41)}$.

Já se encontram bem estabelecidos os benefícios decorrentes da implantação precoce do tratamento para a $A R$, que deve ser conduzido de forma agressiva, visando à remissão do processo inflamatório. Porém, ainda persistem diversas dúvidas e controvérsias sobre a terapia de escolha e o uso de agentes biológicos ${ }^{(17)}$.

A avaliação da atividade da doença deve ser feita periodicamente até que o paciente entre em remissão da doença. Sugere-se a repetição de exames radiográficos de mãos, punhos e pés a cada ano para acompanhamento evolutivo das erosões ósseas. 


\section{Discussão e conclusão}

A AR é uma doença autoimune e debilitante, cuja etiologia exata ainda permanece desconhecida. O caráter agressivo da AR ressalta a importância de seu reconhecimento precoce, o que aumenta significativamente as perspectivas de melhora clínica e remissão.

A dificuldade em estabelecer um diagnóstico precoce com base nas manifestações clínicas da doença ressalta o valor da caracterização dos autoanticorpos como marcadores precoces e de prognóstico de DAls como a AR. Esses autoanticorpos são atualmente considerados ferramentas de valor relevante tanto na prática clínica como na triagem de populações de risco.

Apesar de seu caráter crônico, o curso da AR pode ser modificado por meio do uso adequado de drogas antirreumáticas. O tratamento da AR é tido atualmente como um processo contínuo e complexo que requer o acompanhamento periódico do paciente, com avaliação do índice de atividade da doença, investigação de manifestações extra-articulares, monitoramento de efeitos colaterais e avaliação da capacidade funcional do paciente. Infelizmente, os benefícios decorrentes do tratamento são frequentemente acompanhados por efeitos adversos acentuados, o que constitui um dos maiores desafios relacionados com a AR.

Não obstante o relevante progresso registrado nos últimos anos, ainda persistem muitas dúvidas e dificuldades no manejo correto da doença, e indivíduos com AR ainda morrem precocemente devido às comorbidades associadas a ela.

\section{Agradecimentos}

Os autores agradecem à Fundação Araucária pelo apoio às pesquisas na área.

\section{Referências}

1. ALAMANOS, Y.; VOULGARI, P. V.; DROSOS, A. A. Incidence and prevalence of rheumatoid arthritis, based on the 1987 American College of Rheumatology criteria: a systematic review. Semin Arthritis Rheum, v. 36, p. 182-8, 2006

2. ALBANI, S.; CARSON, D.A. Etiology and pathogenesis of rheumatoid arthritis. In: KOOPMAN, W. J. Arthritis and allied conditions. A textbook of rheumatology. 13. ed., Baltimore: Williams \& Wilkins, 1997, p. 979-92.

3. ALESSANDRI, C. et al. The role of anti-cyclic cytrullinate antibodies testing in rheumatoid arthritis. Clinic Rev Allerg Immunol, v. 34, p. 45-9, 2008.

4. ALETAHA, D. et al. 2010 Rheumatoid arthritis classification criteria. Arthritis Rheum, v. 62, n. 9, p. 2569-81, 2010.

5. ANNE, C. Th17 cells in inflammatory conditions. Rev Diabetic Stud, v. 3, p. 72-5, 2006.

6. ARBUCKLE, M. R. etal. Development of autoantibodies before the clinical onset of systemic lupus erythematosus. N Engl J Med, v. 349, p. 1526-33, 2003.

7. ARNETT, F. C. et al. The American Rheumatism Association 1987 revised criteria for the classification of rheumatoid arthritis. Arthritis Rheum, v. 31, p. 315-24, 1988.

8. BALSA, A. et al. Influence of HLA DRB1 alleles in the susceptibility of rheumatoid arthritis and the regulation of antibodies against citrullinated proteins and rheumatoid factor. Arthritis Res Ther, v. 12, n. 2 , p. R62, 2010.

9. BUCKLEY, C. D. Science, medicine, and the future: treatment of rheumatoid arthritis. BMJ, v. 315 , p. 236-8, 1997.
10. BUREK, C. L.; ROSE, N. R. Autoantibodies. In: COLVIN, R. B.; BHAN, A. K.; McMLUSKEY, R. T. Diagnostic immunopathology. 2. ed. New York: Raven Press, 1995. p. 207-30.

11. CAPPUZZO, K. A. Diagnosis and treatment of early active rheumatoid arthritis. Consult Pharm, v. 23, n. 12, p. 956-61, 2008

12. CLAVEL, C. et al. Induction of macrophage secretion of TNF $\alpha$ through Fc $\gamma$ receptor lla engagement by rheumatoid arthritis-specific autoantibodies to citrullinated proteins complexed with fibrinogen. Arthritis Rheum, v. 58, n. 3, p. 678-88, 2008.

13. CONSTANTINESCU, F. et al. Racial disparities in treatment preferences for rheumatoid arthritis. Med Care, v. 47, n. 3, p. 350-5, 2009.

14. CRISCIONE, L. G.; St. CLAIR, E. W. Tumor necrosis factoralfa antagonists for the treatment of rheumatic diseases. Curr Opin Rheumatol, v.14, p. 204-11, 2002.

15. DE PABLO, P. et al. Periodontitis in systemic rheumatic diseases. Nat Rev Rheumatol, v. 5, n. 4, p. 218-24, 2009.

16. EGSMOSE, C. et al. Patients with rheumatoid arthritis benefit from early $2^{\text {nd }}$ line therapy: 5-year followup of a prospective double blind placebo controlled study. J Rheumatol, v. 22, p. 2208-13, 1995.

17. EMERY, P. Treatment of rheumatoid arthritis. BMJ, v. 332, n. 7534, p. 152-5, 2006.

18. FABIEN, N. et al. Prevalence of autoantibodies to cyclic citrullinated peptide in patients with rheumatic diseases other than rheumatoid arthritis: a French multicenter study. Clin Rev Allergy Immunol, v. 34, n. 1, p. 40-4, 2008. 
19. FELDMANN, M.; BRENNAN, F. M. Rheumatoid arthritis. Cell, v. 85, p. 307-10, 1996.

20. FELSON, D. T. Comparing the prevalence of rheumatic diseases in China with the rest of the world. Arthritis Res Ther, v. 10, n. 1, p. 106, 2008.

21. FERUCCI, E. D.; TEMPLIN, D. W.; LANIER, A. P. Rheumatoid arthritis in American Indians and Alaska natives: a review of the literature. Semin Arthritis Rheum, v. 34, n. 4, p. 662-7, 2005.

22. FIKE, D. J. Non-organ-specific autoimmune disease. In: SHEEHAN, C. Clin Immunol. 2. ed. Philadelphia: Lippincott, 1997. p. 283-96.

23. FIRESTEIN, G. S. Evolving concepts of rheumatoid arthritis. Nature, v. 5, n. 423, p. 356-61, 2003.

24. GLEISSNER, C. et al. The role of risk factors for periodontal disease in patients with rheumatoid arthritis. Eur J Med Res, v. 3, n. 8, p. 387-92, 1998.

25. GOELDNER, I. et al. Anti-cyclic citrullinated peptide antibodies and rheumatoid factor in rheumatoid arthritis patients and relatives from Brazil. Rheumatology (Oxford), v. 49, n. 8, p. 1590-3, 2010.

26. GOODSON, N. J.; FARRAGHER, T. M.; SYMMONS, D. P. Rheumatoid factor, smoking, and disease severity: associations with mortality in rheumatoid arthritis. J Rheumatol, v. 35, n. 6, p. 945-9, 2008.

27. GRANT, S. F. et al. The inheritance of rheumatoid arthritis in Iceland. Arthritis Rheum, v. 44, n. 10, p. 2247-54, 2001.

28. HABASH-BSEISO, D. E. et al. Serologic testing in connective tissue diseases. Clin Med Res, v. 3, n. 3, p. 190-3, 2005.

29. HARNEY, S.; WORDSWORTH, B. P. Genetic epidemiology of rheumatoid arthritis. Tissue Antigens, v. 60, n. 6, p. 465-73, 2002.

30. HARTY, L. C.; VEALE, D.J. Irish smokers with rheumatoid arthritis suffer more than their nonsmoking counterparts. J Rheumatol, v. 37, n. 5, p. 1062, 2010.

31. HELLMANN, D. B.; STONE, J. H. Arthritis \& musculoskeletal disorders. In: TIERNEY, L. M. et al. Curr Med Diag Treat. 43. ed. New York: McGraw-Hill, 2004. p. 797-825.

32. INBODEM, J. B. The immunopathogenesis of rheumatoid arthritis. Annu Rev Pathol Mech Dis, v. 4, p. 417-34, 2009.

33. IOAN-FACSINAY, A. et al. Marked differences in fine specificity and isotype usage of the anti-citrullinated protein antibody in health and disease. Arthritis Rheum, v. 58, p. $3000-8,2008$.

34. JASKOWSKI, T. D. et al. Relationship between rheumatoid factor isotypes and IgG anti cyclic citrulinated peptide antibodies. J Rheumatol, v. 37, n. 8, p. 1582-8, 2010.

35. JORGENSEN, C. et al. IgA isotype rheumatoid factor in rheumatoid arthritis: clinical implications. Clin Exp Rheumatol, v. 14, n. 3, p. 301-4, 1996.

36. KINLOCH, A. et al. Synovial fluid is a site of citrullination of autoantigens in inflammatory arthritis. Arthritis Rheum, v. 58, n. 8, p. 2287-95, 2008.

37. KLARESKOG, L. et al. A new model for an etiology of rheumatoid arthritis: smoking may trigger HLA-DR (shared epitope)-restricted immune reactions to autoantigens modified by citrullination. Arthritis Rheum, v. 54, n. 1, p. 38-46, 2006.
38. KLARESKOG, L.; WEDREN, S.; ALFREDSSON, L. On the origins of complex immune-mediated disease: the example of rheumatoid arthritis. J Mol Med, v. 87, n. 4, p. 357-62, 2009.

39. KOUMANTAKI, Y. et al. Family history as a risk factor for rheumatoid arthritis: a case-control study. J Rheumatol, v. 24 , n. 8, p. 1522-6, 1997

40. KWOH, C. K. et al. Age, sex, and the familial risk of rheumatoid arthritis. Am J Epidemiol, v. 144, n. 1, p. 15-24, 1996.

41. LEE, D. M.; WEINBLATT, M. E. Rheumatoid arthritis. Lancet, v. 358, p. 903-11, 2001.

42. LUNDKVIST, J.; KASTANG, F.; KOBELT, G. The burden of rheumatoid arthritis and access to treatment: health burden and costs. Eur J Health Econ, v. 8, suppl. 2, p. S49-60, 2008.

43. LUNDSTRÖM, E. et al. Gene-environment interaction between the DRB1 shared epitope and smoking in the risk of anti-citrullinated protein antibody-positive rheumatoid arthritis. Arthritis Rheum, v. 60, n. 6, p. 1597-603, 2009.

44. MacGREGOR, A. J. et al. Characterizing the quantitative genetic contribution to rheumatoid arthritis using data from twins. Arthritis Rheum, v. 43, p. 30-7, 2000.

45. MAJITHIA, V.; GERACI, S. A. Rheumatoid arthritis: diagnosis and management. Am J Med, v. 120, n. 11, p. 936-9, 2007.

46. MAJKA, D. S. et al. Duration of preclinical RA-related autoantibody positivity increases in subjects with older age at time of disease diagnosis. Ann Rheum Dis, v. 67, p. 801-7, 2008.

47. MARQUES, J. F. N. et al. Estudo multicêntrico da prevalência da artrite reumatóide do adulto em amostras da população brasileira. Rev Bras Reumatol, v. 33, n. 5, p. 169-73, 1993.

48. MICHOU, L. et al. Prevalence and distribution of autoimmune diseases in 368 rheumatoid arthritis families. J Rheumatol, v. 35, n. 5, p. 1-7, 2008.

49. MIOSSEC, P.; KORN, T.; KUCHROO, V. K. Interleukin-17 and type 17 helper T cells. N Engl J Med, v. 361, p. 888-98, 2009.

50. NELL-DUXNEUNER, V. et al. Autoantibody profiling in patients with very early rheumatoid arthritis - a follow-up study. Ann Rheum Dis, v. 69, n. 1, p. 169-74, 2009.

51. NIELEN, M. M. et al. Specific autoantibodies precede the symptoms of rheumatoid arthritis: a study of serial measurements in blood donors. Arthritis Rheum, v. 50, n. 2, p. 380-6, 2004.

52. NISHIMURA, K. et al. Meta-analysis: diagnostic accuracy of anti-cyclic citrullinated peptide antibody and rheumatoid factor for rheumatoid arthritis. Ann Intern Med, v. 146, n. 11, p. 797-808, 2007

53. OZBALKAN, Z. et al. An update on the relationships between rheumatoid arthritis and atherosclerosis. Atherosclerosis, v. 212, n. 2, p. 377-82.

54. PADYUKOV, L. et al. A gene-environment interaction between smoking and shared epitope genes in HLADR provides a high risk of seropositive rheumatoid arthritis. Arthritis Rheum, v. 50, n. 10, p. 3085-92, 2004. 
55. PARADOWSKA, A. et al. The function of interleukin 17 in the pathogenesis of rheumatoid arthritis. Arch Immunol Ther Exp, v. 55, n. 5, p. 329-34, 2007.

56. RANTAPÄÄ-DAHLQVIST, S. et al. Antibodies against cyclic citrullinated peptide and IgA rheumatoid factor predict the development of rheumatoid arthritis. Arthritis Rheum, v. 48, n. 10, p. 2741-9, 2003.

57. REPARON-SCHUIJT, C. C. etal. Secretion of anti-citrullinecontaining peptide antibody by $B$ lymphocytes in rheumatoid arthritis. Arthritis Rheum, v. 44, n. 1, p. 41-7, 2001.

58. ROJAS-VILLARRAGA, A. et al. Familial disease, the HLA-DRB1 shared epitope and anti-CCP antibodies influence time at appearance of substantial joint damage in rheumatoid arthritis. J Autoimmun, v. 32, n. 1, p. 64-9, 2009.

59. SACK, K. E.; FYE, K. H. Doenças reumáticas. In: STITES, D. P.; TERR, A. I.; PARSLOW, T. G. Imunologia médica. 9. ed. Rio de Janeiro: Guanabara Koogan, 2000. p. 353-70.

60. SHINOMIYA, F. et al. Life expectancies of Japanese patients with rheumatoid arthritis: a review of deaths over a 20-year period. Mod Rheumatol, v. 18, n. 2, p. 165-9, 2008.

61. SOKKA, T. et al. Women, men, and rheumatoid arthritis: analyses of disease activity, disease characteristics, and treatments in the QUEST-RA study. Arthritis Res Ther, v. 11, p. R7, 2009.

62. STAHL, E. A. et al. Genome-wide association study metaanalysis identifies seven new rheumatoid arthritis risk loci. Nat Genet, v. 42, n. 6, p. 508-14, 2010.

63. SUREH, E. Recent advances in rheumatoid arthritis. Post Grad Med J, v. 86, p. 243-250, 2010.

64. SVENDSEN, A. J. et al. Relative importance of genetic effects in rheumatoid arthritis: historical cohort study of Danish nationwide twin population. BMJ, v. 324, n. 7332, p. 264-6, 2002.

65. TAN, R. J. L. et al. Investigation of rheumatoid arthritis susceptibility genes identifies association of AFF3 and CD226 variants with response to anti-tumour necrosis factor Treatment. Ann Rheum Dis, v. 69, n. 6, p. 1029-35, 2010.

66. TEHLIRIAN, C. V.; BATHON, J. M. Rheumatoid arthritis: clinical and laboratory manifestations. In: STONE, J. H.; CROFFORD, L. J.; WHITE, P. H. Primer on the rheumatic diseases. 30. ed. New York: Springer, 2008. p. $114-21$.

67. TOUSSIROT, E.; ROUDIER, J. Epstein-Barr virus in autoimmune diseases. Best Pract Res Clin Rheumatol, v. 22, n. 5, p. 883-96, 2008.

68. TSAKONAS, E. et al. Consequences of delayed therapy with second-line agents in rheumatoid arthritis: a 3 year followup on the Hydroxychloroquine in Early Rheumatoid Arthritis (HERA) study. J Rheumatol, v. 27, p. 623-9, 2000.

69. TURESSON, C.; MATTESON, E. L. Genetics of rheumatoid arthritis. Mayo Clin Proc, v. 81, n. 1, p. 94-101, 2006.

70. TURESSON, C.; MATTESON, E. L. Vasculitis in rheumatoid arthritis. Curr Opin Rheumatol, v. 21, n. 1, p. 35-40, 2009.

71. UHLIG, T. et al. Rheumatoid arthritis is milder in the new millennium: health status in RA patients 1994-2004. Ann Rheum Dis, v. 67, n. 12, p. 1710-5, 2008.

72. VAN DER CRUYSSEN, B. et al. Anti-citrullinated peptide antibodies may occur in patients with psoriatic arthritis. Ann Rheum Dis, v. 64, n. 8, p. 1145-9, 2005.

73. VAN DER WOUDE, D. et al. Epitope spreading of the anti-citrullinated protein antibody response occurs before disease onset and is associated with the disease course of early arthritis. Ann Rheum Dis, v. 69, n. 8, p. 1554-61, 2010.

74. VAN VOLLENHOVEN, R. F. Sex differences in rheumatoid arthritis: more than meets the eye. BMC Med, v. 30, n. 7, p. 12, 2009.

75. VISSCHER, P. M.; HILL, W. G.; WRAY, N. R. Heritability in the genomics era - concepts and misconceptions. Nat Rev Genet, v. 9, p. 255-66, 2008.

76. VOSSENAAR, E. R. et al. Rheumatoid arthritis specific anti-Sa antibodies target citrullinated vimentin. Arthritis Res Ther, v. 6, n. 2, p. R142-50, 2004a.

77. VOSSENAAR, E. R. et al. The presence of citrullinated proteins is not specific for rheumatoid synovial tissue. Arthritis Rheum, v. 50, n. 11, p. 3485-94, 2004b.

78. VOSSENAAR, E. R.; VAN VENROOIJ, W. J. Citrullinated proteins: sparks that may ignite the fire in rheumatoid arthritis. Arthritis Res Ther, n. 6, p. 107-11, 2004.

79. YOUNG, A.; KODURI, G. Extra-articular manifestations and complications of rheumatoid arthritis. Best Pract Res Clin Rheumatol, v. 21, n. 5, p. 907-27, 2007. 